\title{
Gases as Precursory Signals: Experimental Simulations, New Concepts and Models of Magma Degassing
}

\author{
M. Pichavant, N. Le Gall and B. Scaillet
}

\begin{abstract}
Volatile release during magma ascent in volcanic conduits (magma degassing) forms the basis for using volcanic gases as precursory signals. Recent high temperature high pressure experimental simulations have yielded results that challenge key assumptions related to magma degassing and are important for the interpretation of glass inclusion and gas data and for using volcanic gas as precursory signals. The experimental data show that, for ascent rates expected in natural systems, pure $\mathrm{H}_{2} \mathrm{O}$ basaltic melts will evolve mostly close to equilibrium when decompressed from 200 to $25 \mathrm{MPa}$. In the same way, degassing of $\mathrm{H}_{2} \mathrm{O}-\mathrm{S}$ species evolves at near equilibrium, although this conclusion is limited by the number of $S$ solubility data available for basaltic melts. However, degassing of $\mathrm{CO}_{2}$ is anomalous in all studies, whether performed on basaltic or rhyolitic melts. $\mathrm{CO}_{2}$ stays concentrated in the melt at levels far exceeding solubilities. The anomalous behaviour of $\mathrm{CO}_{2}$, when associated with near equilibrium $\mathrm{H}_{2} \mathrm{O}$ losses, yields post-decompression glasses with $\mathrm{CO}_{2}$ concentrations systematically higher than equilibrium degassing curves. Therefore, there is strong
\end{abstract}

M. Pichavant $(\bowtie) \cdot$ N. Le Gall · B. Scaillet

CNRS, Orléans, France

e-mail: michel.pichavant@cnrs-orleans.fr experimental support for disequilibrium degassing during ascent of $\mathrm{CO}_{2}$-bearing magmas. The existence of volatile concentration gradients around nucleated gas bubbles suggests that degassing is controlled by the respective mobilities (diffusivities) of volatiles within the melt. The recently formulated diffusive fractionation model reproduces the main characteristics, especially the volatile concentrations, of experimental glasses. The model also shows that the gas phase is more $\mathrm{H}_{2} \mathrm{O}$-rich than expected at equilibrium because $\mathrm{CO}_{2}$ transfer toward the gas phase is hampered by its retention within the melt. However, only integrated gas compositions are calculated. Similarly, only bulk experimental fluid compositions are determined in recent experiments. Thus, constraints on the local gas phase are becoming necessary for the application to volcanoes. This stresses the need for the direct analysis of gas bubbles nucleated in decompression experiments. Pre-eruptive changes in volcanic $\mathrm{CO}_{2} / \mathrm{SO}_{2}$ and $\mathrm{H}_{2} \mathrm{O} / \mathrm{CO}_{2}$ gas ratios are interpreted to reflect different pressures of gas-melt segregation in the conduit, an approach that assume gas-melt equilibrium. However, if disequilibrium magma degassing is accepted, the use of volatile saturation codes is no longer possible and caution must be exercised with the application of local equilibrium to volcanic gases. Future developments in the interpretation of gas data require progress 
from both sides, experimental and volcanological. One priority is to reduce the gap in scales between experiments and gas measurements.

\section{Keywords}

Magma ascent - Decompression experiments Disequilibrium degassing $\cdot$ Volatile diffusion Gas compositions

\section{Extended Abstract}

Volcanic gases are one of the main tools to monitor changes in the activity of volcanoes and forecast their eruption. Magma ascent toward the surface is associated with the exsolution of volatiles initially dissolved in the melt, a process designated as "magma degassing". Classically, the interpretation of volcanic gases relies on the assumption that degassing takes place at equilibrium. However, several observations $\left(\mathrm{CO}_{2}\right.$ contents of basaltic seafloor glasses, $\mathrm{H}_{2} \mathrm{O}$ and $\mathrm{CO}_{2}$ concentrations in glass inclusions, explosive basaltic volcanism) do not fit easily in such a model. Recently, decompression, ascent and degassing of magmas in volcanic conduits have been simulated by high temperature high pressure experiments. Results from these simulations stress the need to critically reconsider the whole mechanism of degassing in basaltic but also rhyolitic magmas. The new experimental data show that, at the decompression rates tested, pure $\mathrm{H}_{2} \mathrm{O}$ basaltic melts will evolve mostly close to equilibrium when decompressed from 200 to $25 \mathrm{MPa}$. In the same way, degassing of $\mathrm{H}_{2} \mathrm{O}-\mathrm{S}$ species evolves at near equilibrium, although this conclusion is limited by the number of S solubility data available for basaltic melts. Degassing of $\mathrm{CO}_{2}$ is anomalous in all studies, whether performed on basaltic or rhyolitic melts. $\mathrm{CO}_{2}$ stays concentrated in the melt at levels far exceeding solubilities. The anomalous behaviour of $\mathrm{CO}_{2}$, when associated with near equilibrium $\mathrm{H}_{2} \mathrm{O}$ losses, yields post-decompression glasses with $\mathrm{CO}_{2}$ concentrations systematically higher than equilibrium degassing curves. Therefore, there is strong experimental support for disequilibrium degassing during ascent of $\mathrm{CO}_{2}$-bearing magmas. The existence of volatile concentration gradients around nucleated gas bubbles suggests that degassing is controlled by the respective mobilities (diffusivities) of volatiles within the melt. The contrasted diffusivities of dissolved volatile species (in particular $\mathrm{H}_{2} \mathrm{O}$ and $\mathrm{CO}_{2}$ ) selectively limit their transfer toward the gas phase for timescales typical for magma ascent. The diffusive fractionation model recently formulated reproduces the main characteristics, especially the volatile concentrations, of experimental glasses. It provides a framework to interpret the new experimental observations and the systematic deviations from equilibrium observed in $\mathrm{CO}_{2}$-bearing systems, although coupling between volatile diffusion and vesiculation requires a more elaborate treatment. The model also shows that the gas phase is more $\mathrm{H}_{2} \mathrm{O}$-rich than expected at equilibrium because $\mathrm{CO}_{2}$ transfer toward the gas phase is hampered by its retention within the melt. However, only integrated gas compositions are calculated. In the same way, only bulk experimental fluid compositions are determined in recent experiments. Since the gas phase is essential for the application to volcanoes, constraints on the local gas phase are becoming necessary. Compositions of gas bubbles in decompression experiments must be linked not only with pressure but also with volatile concentrations of local melts, specific degassing textures and mechanisms. As a way in this direction, local gas-melt equilibrium assumes that chemical equilibrium persists at the local scale, despite evidence for disequilibrium at larger scales. However, there are alternative ways to constrain the composition of nucleated gas bubbles, thus stressing the need for their direct analysis in decompression experiments. Pre-eruptive changes in $\mathrm{CO}_{2} / \mathrm{SO}_{2}$ and, in some cases, $\mathrm{H}_{2} \mathrm{O} / \mathrm{CO}_{2}$ gas ratios observed at several basaltic volcanoes are generally interpreted to reflect different pressures of gas-melt segregation in the conduit, an approach that assume gas-melt equilibrium. However, if disequilibrium magma degassing is accepted, volatile saturation codes can no longer be directly used. Caution also must be exercised with the application of local gas-melt equilibrium to volcanic gases which are probably 
closer to integrated rather than to local compositions. Future developments in the interpretation of gas data require progress from both sides, experimental and volcanological. One priority is to reduce the gap in scales between experiments and gas measurements to refine interpretations of gas compositions as unrest signals.

\section{Magma Degassing and Volcanic Gases as Precursory Signals}

Volcanic gases are one of the main tools used to monitor changes in the activity of volcanoes and forecast their eruption. This approach is rooted in the strong pressure dependence of the solubility of volatiles (mainly $\mathrm{H}_{2} \mathrm{O}, \mathrm{CO}_{2}, \mathrm{SO}_{2}, \mathrm{H}_{2} \mathrm{~S}, \mathrm{Cl}$ ) in silicate melts. Accordingly, magma ascent toward the surface is associated with the exsolution of volatiles initially dissolved in the melt, a process designated as "magma degassing". The different volatiles have contrasted solubilities in silicate melts and, therefore, are expected to react differently to decompression. This forms the basis for using volcanic gas ratios to infer magma ascent and depth of gas segregation in volcanic conduits. For example, the sudden increase of gas $\mathrm{CO}_{2} / \mathrm{SO}_{2}$ ratio has been used as an indication for deep magma recharge at Stromboli (Aiuppa et al. 2010). At Soufriere Hills volcano (Montserrat), a correlation has been noted between gas $\mathrm{HCl} / \mathrm{SO}_{2}$ and the level of shallow activity as marked by the rate of lava extrusion and dome growth (Christopher et al. 2010; Edmonds et al. 2010).

Classically, the interpretation of volcanic gases relies on the assumption that degassing takes place at equilibrium. In the case of basaltic magmas, this assumption is supported by the high temperatures, low viscosities and high volatile diffusivities (Sparks et al. 1994). Vesiculation (i.e., the combined processes of bubble nucleation, growth and coalescence) is thought to be relatively easy in basaltic melts and degassing of basaltic magma is classically viewed as an equilibrium process. However, several observations do not fit easily in such a model. They include (1) the existence of basaltic seafloor glasses often supersaturated in $\mathrm{CO}_{2}$ (e.g., Aubaud et al. 2004), (2) the occurrence of glass inclusions with $\mathrm{H}_{2} \mathrm{O}$ and $\mathrm{CO}_{2}$ concentrations inconsistent with closed system equilibrium degassing (e.g., Metrich et al. 2010) and (3) the occurrence of explosive basaltic volcanism (e.g., Head and Wilson 2003) which implies sudden rather than gradual release of volatiles.

Recently, decompression and ascent of basaltic magmas in volcanic conduits has been simulated by high temperature high pressure petrological experiments. These simulations stress the need to critically reconsider the whole mechanism of degassing in basaltic but also more silicic magmas. In particular, the assumption of equilibrium degassing is now becoming increasingly challenged. This has major implications for the interpretation of glass inclusion and gas data and, more generally, for the use of volcanic gas as precursory signals. In this Chapter, first, the recent experimental simulations are reviewed. We show that they all demonstrate an anomalous behaviour for $\mathrm{CO}_{2}$ which tends to stay dissolved within the melt at concentrations too high for equilibrium. Second, the diffusive fractionation model which has been proposed to account for the new experimental observations is described and critically discussed. Finally, the implications of disequilibrium degassing for experimental fluid compositions and the interpretation of volcanic gas data as precursory signals are explored.

\section{Experimental Simulations}

\subsection{Basaltic Systems}

Following early work on systems with only pure $\mathrm{CO}_{2}$ (Lensky et al. 2006), decompression experiments on hydrous basaltic melts have been carried out recently by Pichavant et al. (2013) at $1150-1180{ }^{\circ} \mathrm{C}$, for initial pressures of $200-$ $250 \mathrm{MPa}$, final pressures of 100,50 and $25 \mathrm{MPa}$ and for decompression rates between $\sim 1.5$ down to $0.25 \mathrm{~m} / \mathrm{s}$. Melts from Stromboli, pre-synthesized to incorporate dissolved $\mathrm{H}_{2} \mathrm{O}$ (2.7-3.8 wt\%) and $\mathrm{CO}_{2}$ (600-1300 ppm), were 
used as starting materials. The experiments were of continuous decompression type, and both constant (one ramp) and variable (two ramps) decompression rates were imposed. Final melt $\mathrm{H}_{2} \mathrm{O}$ concentrations were homogeneous and always close to equilibrium solubility values. In contrast, the rate of vesiculation was found to control the final melt $\mathrm{CO}_{2}$ concentration. High vesicularity charges had glass $\mathrm{CO}_{2}$ concentrations that follow theoretical equilibrium degassing paths whereas glasses from low vesicularity charges showed marked deviations from equilibrium, with $\mathrm{CO}_{2}$ concentrations up to one order of magnitude higher than equilibrium solubilities (Fig. 1a). The experimental results were interpreted in light of the slower diffusivity of $\mathrm{CO}_{2}$ relative to $\mathrm{H}_{2} \mathrm{O}$ in basaltic melts.

Yoshimura (2015) decompressed a natural evolved basaltic melt containing dissolved $\mathrm{H}_{2} \mathrm{O}$ and $\mathrm{CO}_{2}$ at $1200{ }^{\circ} \mathrm{C}$ and between 1000 and $500 \mathrm{MPa}$. The short decompression duration of 10 min over this pressure interval simulates a very fast ascent rate $(\sim 32 \mathrm{~m} / \mathrm{s}$ for a rock density of $2650 \mathrm{~kg} / \mathrm{m}^{3}$ ). A vesiculated glass was produced and Fourier Transform Infrared Spectroscopy (FTIR) profiles revealed large $\mathrm{CO}_{2}$ concentration gradients in the melt adjacent to gas bubbles. In contrast, the melt $\mathrm{H}_{2} \mathrm{O}$ content was almost constant throughout the sample. The glass volatile concentration data cover a near vertical trend in the $\mathrm{H}_{2} \mathrm{O}-\mathrm{CO}_{2}$ diagram (Fig. 1a).

Le Gall and Pichavant (2016a) extended the decompression experiments performed by Pichavant et al. (2013), using essentially the same procedures and materials. Three starting volatile compositions were investigated: series \#1 (4.91 wt\% $\mathrm{H}_{2} \mathrm{O}$, no $\mathrm{CO}_{2}$ ), series \#2 $\left(2.41 \pm 0.04\right.$ wt $\% \mathrm{H}_{2} \mathrm{O}, 973 \pm 63$ ppm $\mathrm{CO}_{2}$ ) and series \#3 $\left(0.98 \pm 0.16 \mathrm{wt} \% \quad \mathrm{H}_{2} \mathrm{O}\right.$, $\left.872 \pm 45 \mathrm{ppm} \mathrm{CO}_{2}\right)$. The volatile-bearing glasses were synthesized at $1200{ }^{\circ} \mathrm{C}$ and $200 \mathrm{MPa}$, then continuously decompressed at a fast decompression rate of $3 \mathrm{~m} / \mathrm{s}$ in the pressure range $150-25 \mathrm{MPa}$ and then rapidly quenched. Post-decompression glasses were characterized texturally by X-ray microtomography. Volatile equilibrium was reached or approached during decompression in all series \#1 melts with just water. In contrast, disequilibrium degassing occurred systematically in series \#2 and \#3 melts which retained elevated $\mathrm{CO}_{2}$ concentrations (Fig. 1a). In similar experiments performed on the same three glass series but at a slower decompression rate of $1.5 \mathrm{~m} / \mathrm{s}$, Le Gall and Pichavant (2016b) found that series \#1 $\left(\mathrm{CO}_{2^{-}}\right.$ free) melts followed equilibrium degassing until $100 \mathrm{MPa}$ final pressure $\left(\mathrm{P}_{\text {fin }}\right)$. But at both 60 and $50 \mathrm{MPa} \mathrm{P}_{\text {fin }}$, a slight $\mathrm{H}_{2} \mathrm{O}$-supersaturation was recognized, associated with a second bubble nucleation event that occurred at $25 \mathrm{MPa}$. In comparison, in series \#2 and \#3 ( $\mathrm{CO}_{2}$-bearing) melts, disequilibrium degassing was systematic, glasses retaining high non-equilibrium $\mathrm{CO}_{2}$ concentrations (Fig. 1a).

The behavior of $\mathrm{H}_{2} \mathrm{O}-, \mathrm{CO}_{2}-$ and S-bearing basaltic melts during decompression was investigated by Le Gall et al. (2015a). Stromboli melts with $2.72 \pm 0.02$ wt $\% \mathrm{H}_{2} \mathrm{O}, 1291 \pm 85 \mathrm{ppm}$ $\mathrm{CO}_{2}$ and $1535 \pm 369 \mathrm{ppm} \mathrm{S}$ were synthesized at $1200{ }^{\circ} \mathrm{C}$ and $200 \mathrm{MPa}$ and then decompressed to final pressures $\left(\mathrm{P}_{\text {fin }}\right)$ ranging from 150 to $25 \mathrm{MPa}$, followed by rapid quenching. The continuous decompressions were conducted at rates of 1.5 and $3 \mathrm{~m} / \mathrm{s}$. During decompression, $\mathrm{S}$ (and $\mathrm{H}_{2} \mathrm{O}$ ) were lost slightly more from the melt than expected from equilibrium degassing models, whilst significant $\mathrm{CO}_{2}$ was retained at elevated concentrations in the melt (Fig. 1a). It was found that the degassing trend recorded by Stromboli glass inclusions could be closely reproduced by the experiments (Fig. 1b; Le Gall et al. 2015a). For andesitic melts, Fiege et al. (2014) observed that the fluid/melt partition coefficient for sulfur increases with the decompression rate. However, the influence of decompression rate on $\mathrm{S}$ degassing was marked only for oxidizing conditions, corresponding to sulfate as the only $\mathrm{S}$ species, thus making necessary to consider the different behaviour of $\mathrm{S}^{2-}$ and $\mathrm{S}^{6+}$ during degassing. 

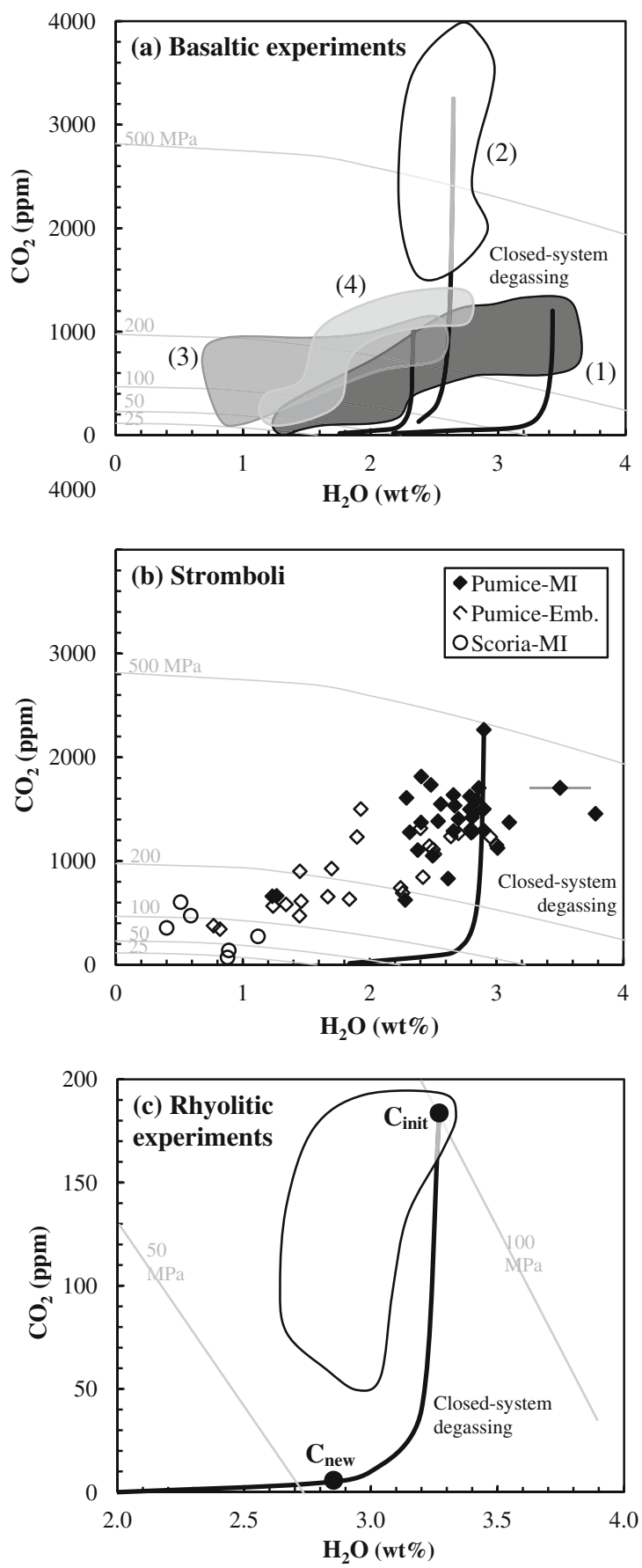

Fig. $1 \mathrm{H}_{2} \mathrm{O}-\mathrm{CO}_{2}$ glass concentration diagrams for a basaltic decompression experiments, b Stromboli glass inclusions and $\mathbf{c}$ rhyolitic decompression experiments. In a, b and c, light grey curves are isobars labelled with pressure in $\mathrm{MPa}$. In a, fields for post-decompression glasses are distinguished with (1) referring to Pichavant et al. (2013), (2) to Yoshimura (2015), (3) to Le Gall and Pichavant (2016a, b) and (4) to Le Gall et al. (2015a). Black curves are closed-system equilibrium degassing trajectories redrawn from the original figures (Pichavant et al. 2013; Yoshimura 2015; Le Gall and Pichavant 2016a, b; Le Gall et al. 2015a). In b, the glass inclusion data are from Metrich et al. (2010). MI: glass inclusions, Emb: embayments. In c, the glass data field and the bold theoretical equilibrium closed-system degassing curve are redrawn from Yoshimura (2015). $C_{\text {init }}$ and $C_{\text {new }}$ are the composition of the pre-decompression melt and of the estimated post-decompression melt at the gas-melt interface, respectively (Yoshimura 2015; see also Figs. 5 and 6) 


\subsection{Rhyolitic Systems}

Yoshimura (2015) decompressed a natural rhyolitic melt containing dissolved $\mathrm{H}_{2} \mathrm{O}$ and $\mathrm{CO}_{2}$ from 100 to $50 \mathrm{MPa}$ at $800{ }^{\circ} \mathrm{C}$. The duration of the decompression was $5000 \mathrm{~s}$ corresponding to a decompression rate of $0.38 \mathrm{~m} / \mathrm{s}$ (for a density of $2650 \mathrm{~kg} / \mathrm{m}^{3}$ ). FTIR analysis of the vesiculated glass sample showed $\mathrm{CO}_{2}$ concentration gradients in the melt away from gas bubbles. In contrast, $\mathrm{H}_{2} \mathrm{O}$ was found to be distributed homogeneously within the sample although $\mathrm{H}_{2} \mathrm{O}$ concentrations decreased significantly relative to the pre-decompression melt showing it had reequilibrated. On the $\mathrm{H}_{2} \mathrm{O}-\mathrm{CO}_{2}$ diagram, the glass volatile concentrations define a near vertical array located left of the theoretical equilibrium degassing curve (Fig. 1c).

\subsection{Summary of Experimental Evidence}

In all experiments above, melt vesiculation is the result of decompression, in most cases single-step (constant decompression rate) and, more rarely, multi-step (variable decompression rates, Pichavant et al. 2013). Vesiculation leads to the generation of a gas (or fluid) phase. Volatiles partition between melt and gas, and volatile concentrations in post-decompression glasses evolve from those initially dissolved in pre-decompression glasses. The evaluation of equilibrium vs. disequilibrium degassing is performed by comparing volatile concentrations of post-decompression glasses with theoretical closed-system equilibrium degassing trajectories (Fig. 1). For pure $\mathrm{H}_{2} \mathrm{O}$ melts, this equilibrium trajectory is calculated using the experimental solubility data of Lesne et al. (2011). For $\mathrm{CO}_{2}-$ and S-bearing systems, gas-melt equilibrium thermodynamic models (Newman and Lowenstern 2002; Papale et al. 2006; Burgisser et al. 2015) are used. Results show that pure $\mathrm{H}_{2} \mathrm{O}$ basaltic systems evolve close to equilibrium when decompressed from 200 to $25 \mathrm{MPa}$ with ascent rates of 1.5 and $3 \mathrm{~m} / \mathrm{s}$, although small levels of $\mathrm{H}_{2} \mathrm{O}$ supersaturation are observed below $100 \mathrm{MPa}$ (Le Gall and Pichavant 2016a, b). In the same way, degassing of $\mathrm{S}$ species evolves at near equilibrium (Le Gall et al. 2015a) although the reference equilibrium model (Burgisser et al. 2015) is somewhat uncertain due to the limited number of $\mathrm{S}$ solubility data for calibration. Degassing of $\mathrm{CO}_{2}$ is anomalous in all studies, whether performed on basaltic or rhyolitic melts (Pichavant et al. 2013; Yoshimura 2015; Le Gall and Pichavant 2016a, b; Le Gall et al. 2015a). $\mathrm{CO}_{2}$ stays concentrated in the melt at concentrations far exceeding solubilities (Fig. 1). Except in the very fast basalt decompression experiment of Yoshimura (2015), the anomalous behaviour of $\mathrm{CO}_{2}$ is associated with significant $\mathrm{H}_{2} \mathrm{O}$ losses which results in post-decompression glasses plotting systematically left of theoretical equilibrium degassing trajectories in Fig. 1. We conclude that recent experimental studies strongly support the possibility of disequilibrium degassing, i.e., that ascending melts can keep volatile concentrations (particularly $\mathrm{CO}_{2}$ ) significantly different from those expected from equilibrium modelling. The questions thus arise of (1) the mechanisms responsible for this disequilibrium behaviour and (2) of the consequences of disequilibrium degassing for the composition of the gas phase.

\section{Modelling Disequilibrium Degassing}

\subsection{The Diffusive Fractionation Model}

Both Pichavant et al. (2013) and Yoshimura (2015) observed decoupling between the behaviour of $\mathrm{H}_{2} \mathrm{O}$ and $\mathrm{CO}_{2}$ during experimental decompression and degassing. In both studies, $\mathrm{CO}_{2}$ concentration gradients were found in post-decompression glasses, either around gas bubbles or near the gas-melt interface. In contrast, no such diffusion profiles were identified for $\mathrm{H}_{2} \mathrm{O}$, despite concentrations being lower (in most cases) than in pre-decompression glasses (Pichavant et al. 2013; Yoshimura 2015; Le Gall et al. 2015a; Le Gall and Pichavant 2016a, b).

Pichavant et al. (2013) suggested that two characteristic distances, the gas interface distance 
(either the distance between two bubbles in the melt or the distance to the gas-melt interface) and the volatile diffusion distance (a function of respective diffusivities of volatiles in the melt) control the degassing process. Yoshimura (2015) quantitatively formulated a diffusive fractionation model to describe the ascent and degassing of volatile-bearing magmas. The reader is referred to this work for details about the calculations. The model is based on a diffusivity of $\mathrm{CO}_{2}$ being one $\log$ unit lower than for $\mathrm{H}_{2} \mathrm{O}$ (e.g., Zhang and Ni 2010). Decompression trajectories computed from the model are shown on Fig. 2 for different ascent rates, from $0.1,1,10,100$ to $\infty \mathrm{m} / \mathrm{s}$. Although very high ascent rates (e.g., Peslier et al. 2015) are necessary for degassing trajectories to shift significantly left to the equilibrium reference curve, the modelling results qualitatively reproduce the main characteristics of experimental post-decompression glasses, i.e., the elevated $\mathrm{CO}_{2}$ glass concentrations, the significant $\mathrm{H}_{2} \mathrm{O}$ losses and the melt concentration trends in $\mathrm{H}_{2} \mathrm{O}-\mathrm{CO}_{2}$ diagrams (Fig. 1).
Yoshimura (2015) emphasized the relative simplicity of his model. For example, bubble growth was not considered as in other more elaborated theoretical treatments (e.g., Gonnermann and Manga 2005). Rather than continuously varying boundary (gas-melt) interface volatile concentrations and bubble-bubble distances as in a natural ascending magma, the calculations were performed step-by-step (i.e., at different pressures) along the decompression ramp, with fixed boundary concentrations and bubble-bubble distance (Yoshimura 2015). It is also important to note that the volatile concentrations on Fig. 2 correspond to averages computed by integrating the concentrations in the melt along the diffusion profiles (distance integrated compositions).

Gas phase compositions were calculated by mass balance using the initial volatile concentrations and the average volatile concentrations left in the melt after decompression and degassing (Yoshimura 2015). Results are shown on Fig. 3 and they correspond to compositions

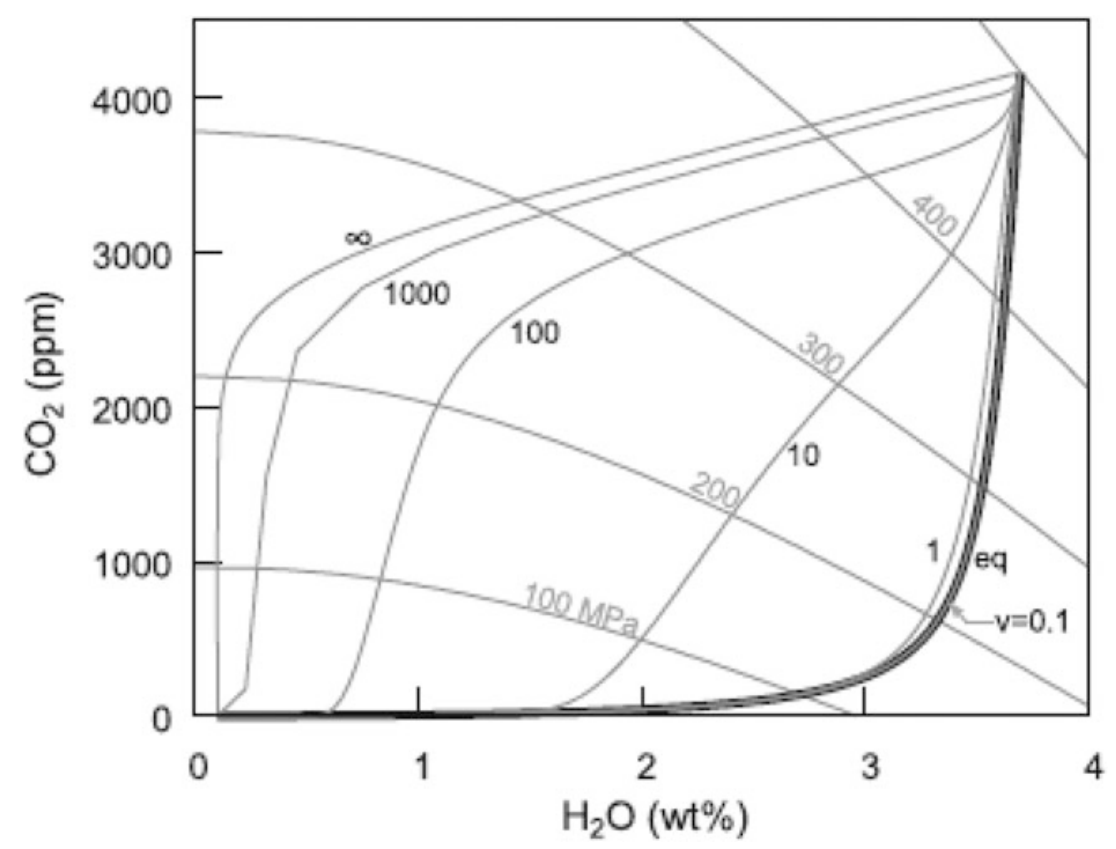

Fig. $2 \mathrm{H}_{2} \mathrm{O}$ and $\mathrm{CO}_{2}$ melt volatile concentrations computed with the diffusive fractionation model for different decompression/ascent rates ( $\mathrm{v}$ from 0.1 to $\infty$, in $\mathrm{m} / \mathrm{s}$ ). Isobars (light curves) are labelled with pressure in MPa.
The heavy curve labelled "eq" is the equilibrium closed-system degassing trajectory as calculated by Yoshimura (2015). Figure redrawn from Yoshimura (2015). See text for details 


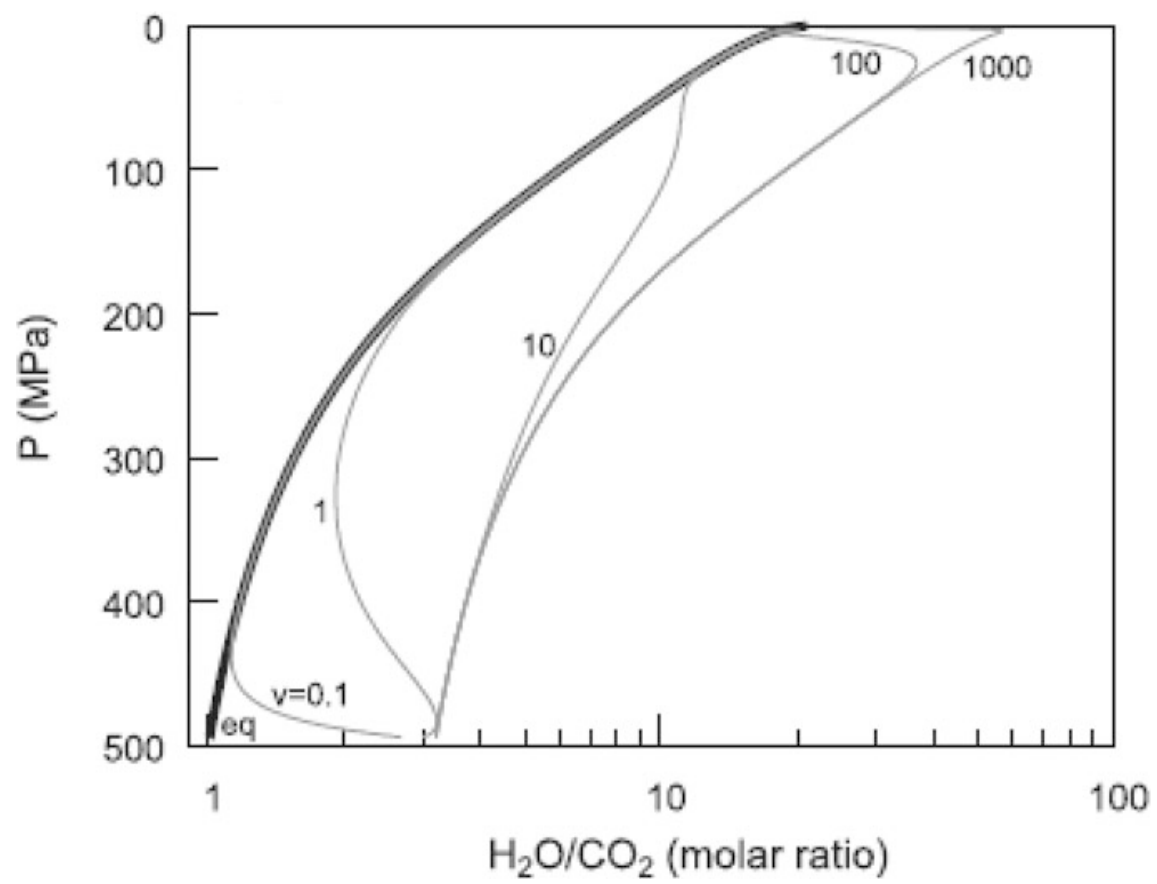

Fig. 3 Variations of the gas $\mathrm{H}_{2} \mathrm{O} / \mathrm{CO}_{2}$ molar ratio (integrated compositions) with pressure computed from the diffusive fractionation model using different decompression/ascent rates ( $\mathrm{v}$ from 0.1 to 1000 , in $\mathrm{m} / \mathrm{s}$ ).

integrated along decompression (pressure integrated compositions). These compositions are more $\mathrm{H}_{2} \mathrm{O}$-rich (higher $\mathrm{H}_{2} \mathrm{O} / \mathrm{CO}_{2}$ ratios) than gases generated under equilibrium degassing.

\subsection{Coupling Between Diffusion and Vesiculation}

Coupling between volatile diffusion and vesiculation is a necessity in diffusive degassing models because vesiculation defines the density of bubbles, their sizes and the distances between them (e.g., Pichavant et al. 2013; Le Gall et al. 2016a, b). This issue was addressed by Yoshimura (2015), although in a relatively simplified manner. The distance between bubbles was defined as being a function of only two variables, the distance between bubbles at the bottom of the decompression column (arbitrary value) and the vesicularity. Vesicularity must change along with decompression and degassing. So, the
The heavy curve labelled "eq" is the equilibrium closed-system degassing trajectory. Figure redrawn from Yoshimura 2015. See text for details

vesicularity term should embody the textural variations associated with magma ascent. In the model of Yoshimura (2015), the vesicularity was computed from the amount of volatiles exsolved upon decompression, using an equation of state for $\mathrm{H}_{2} \mathrm{O}-\mathrm{CO}_{2}$ gas mixtures to calculate the density of the gas and assuming a constant density for the melt. In so doing, it is apparent that only a vesicularity corresponding to equilibrium degassing is considered. Thus, for a given initial bubble-bubble distance, the distance between bubbles in the decompression column depends only on the equilibrium vesicularity. Degassing trajectories (Fig. 2) and integrated gas compositions (Fig. 3) were calculated on this basis.

For comparison, experimental vesicularities, bubble diameters and bubble number densities are shown on Fig. 4 for three series of basaltic melts decompressed from 200 to $25 \mathrm{MPa}$ final pressure $\left(\mathrm{P}_{\text {fin }}\right)$ at $3 \mathrm{~m} / \mathrm{s}$ (Le Gall and Pichavant 2016a). Systematic variations within the three glass series are observed depending on $\mathrm{P}_{\text {fin }}$. In 
most cases, the vesicularity data plot intermediate between the two equilibrium vesicularity curves, which were computed in a similar way than Yoshimura (2015) but only for two end-member cases corresponding to pure $\mathrm{H}_{2} \mathrm{O}$ and pure $\mathrm{CO}_{2}$ gas. The vesicularity data for the series \#1 melts (with pure $\mathrm{H}_{2} \mathrm{O}$ ) are in general much lower than the theoretical vesicularities calculated for pure $\mathrm{H}_{2} \mathrm{O}$ gas. The data also show large changes in bubble sizes and bubble number densities that do not directly correlate with vesicularity. Le Gall and Pichavant (2016a) emphasized that
Fig. 4 Textural data for post-decompression experimental glasses plotted as a function of final pressure $\left(\mathrm{P}_{\text {fin }}\right)$ and comparison with data for natural basaltic pumices (Stromboli, Masaya). Vesicularities (a), bubble diameters (b) and bubble number densities (c) for three series of basaltic melts decompressed from 200 to $150,100,50$ and to $25 \mathrm{MPa}$ $\mathrm{P}_{\text {fin }}$ at $3 \mathrm{~m} / \mathrm{s}$ (Le Gall and Pichavant 2016a).

Pre-decompression melt concentrations, series \#1: 4.91 wt $\% \mathrm{H}_{2} \mathrm{O}\left(\right.$ no $\mathrm{CO}_{2}$ ), series \#2: $2.41 \pm 0.04 \mathrm{wt} \%$ $\mathrm{H}_{2} \mathrm{O}, 973 \pm 63 \mathrm{ppm} \mathrm{CO}_{2}$ and series \#3: $0.98 \pm 0.16 \mathrm{wt} \%$ $\mathrm{H}_{2} \mathrm{O}, 872 \pm 45$ ppm $\mathrm{CO}_{2}$. Note that, for charge $\mathrm{S}+\mathrm{S} 38 \# 1$ which was partially fragmented, the vesicularity (a) and BND (c) data concern the unfragmented part. The bubble diameter data (b) are for both the unfragmented (black symbol) and the fragmented (minimum and maximum values) parts. Figure redrawn from Le Gall and Pichavant (2016a)
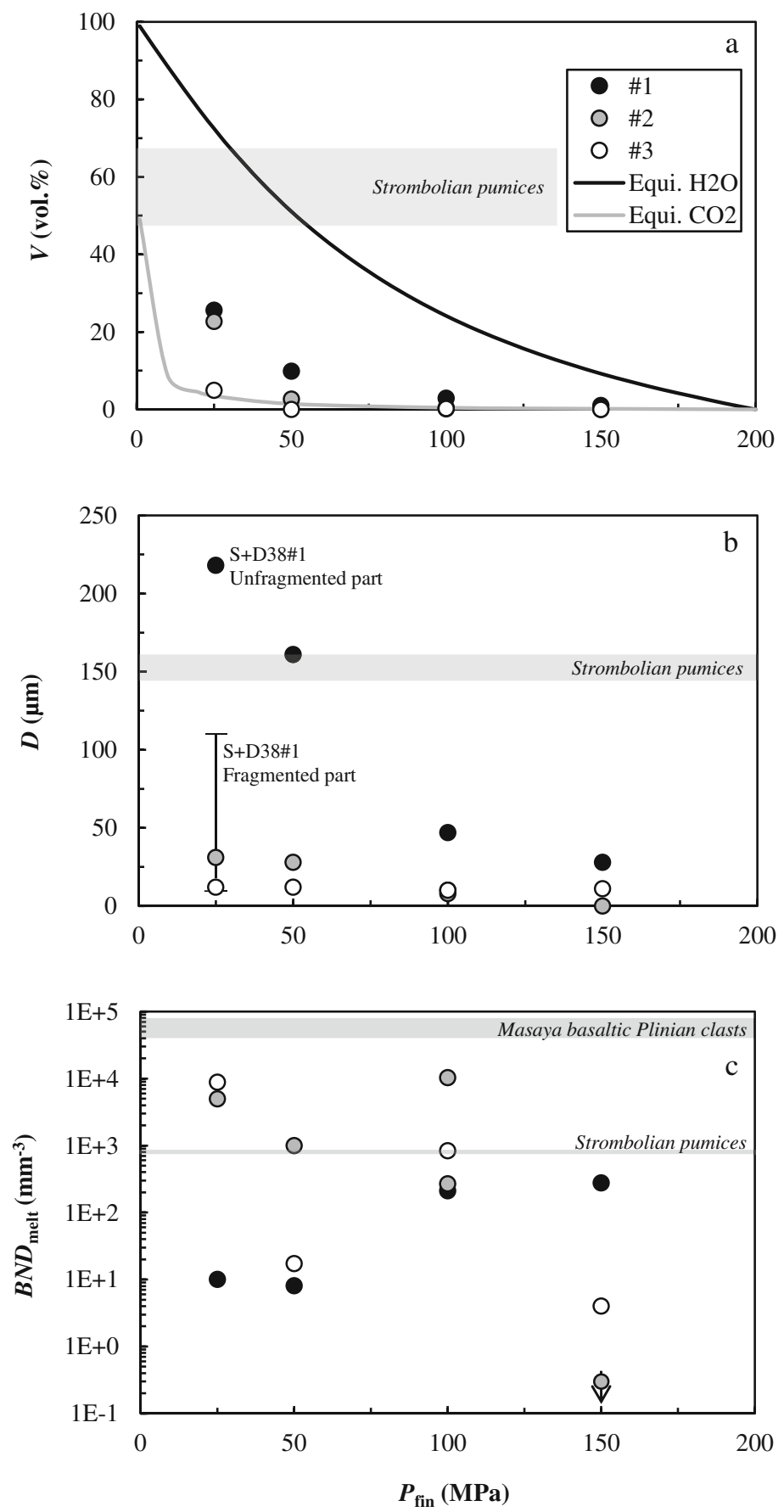
degassing textures result from several processes including bubble nucleation, growth, coalescence, plus buoyancy-driven bubble migration. We conclude that, although the diffusive fractionation model of Yoshimura (2015) provides a basis for coupling volatile diffusion calculations and vesiculation processes, more work is needed to incorporate the complex textural changes associated with ascent of volatile-bearing melts.

\section{Implications for Gas Phase Compositions}

\subsection{Available Data and Models}

Despite the limitations noted above, the diffusive fractionation model provides a framework to interpret the experimental observations and the systematic deviations from equilibrium degassing observed in $\mathrm{CO}_{2}$-bearing systems. However, it should be emphasized that the model uses analytical data (glass volatile concentrations) and physicochemical properties (volatile diffusivities) related only to the melt phase. The question arises of the consequences of disequilibrium degassing for the gas phase composition. It is worth remembering here that the precursory signals come from gas data.

In the decompression experiments summarized above, the gas phase has not been chemically analysed although some mass balance calculations were performed to estimate the composition of the gas phase in the $\mathrm{H}_{2} \mathrm{O}-, \mathrm{CO}_{2}-$ and S-bearing experiments of Le Gall et al. (2015a). However, it is emphasized that, with this method, only bulk experimental gas compositions are provided (charge and pressure integrated compositions). No information is available on the composition of individual bubbles generated during decompression. The gas calculations performed by Yoshimura (2015) also use a similar mass balance approach, i.e., pressure integrated fluid compositions are given. However, the local gas at the gas-melt interface has an equilibrium composition (local gas-melt equilibrium). The differences between the disequilibrium (calculated with the model) and the equilibrium (calculated assuming equilibrium degassing) gases (Fig. 3) is the consequence of $\mathrm{CO}_{2}$ degassing being hampered by its retention within the melt. Therefore, disequilibrium is evidenced in the compositions of the pressure integrated fluids.

\subsection{Composition of Gas Bubbles}

The experiments and the diffusive fractionation model show that melt and gas both evolve under disequilibrium during magma ascent and degassing. For the melt, this conclusion is based either on volatile concentration measurements in glass at some distance of the gas/melt interface (Pichavant et al. 2013; Yoshimura 2015; Le Gall and Pichavant 2015a, 2016a, b) or on average concentrations calculated by integration along diffusion profiles (Yoshimura 2015). For the gas, constraints are available only on integrated compositions (Le Gall et al. 2015a; Yoshimura 2015). Since the gas phase is essential for the application to volcanoes, and given the interpretations proposed for the melt phase, constraints on the gas phase composition at smaller scales are becoming necessary. This requires linking compositions of gas bubbles in decompression experiments not only with pressure but also with volatile concentrations of local melts as well as with degassing textures and mechanisms.

As a way toward this direction, local gas-melt equilibrium can be assumed. This implies that chemical equilibrium persists locally between gas and melt, despite evidence for disequilibrium at larger scales. Therefore, the volatile compositions of melt and gas at the interface are defined by equilibrium partitioning of volatiles between these two phases (e.g., Dixon and Stolper 1995). To illustrate this concept, a schematic representation of the gas-melt interface for a $\mathrm{H}_{2} \mathrm{O}-$ and $\mathrm{CO}_{2}$-bearing melt decompressed isothermally from an initial $\left(\mathrm{P}_{\text {init }}\right)$ to a final $\left(\mathrm{P}_{\text {fin }}\right)$ pressure is shown on Fig. 5a. Initial volatile concentrations $\left(\mathrm{C}_{\text {init }}\right)$, together with the $\mathrm{P}_{\text {init }}$ and $\mathrm{P}_{\text {fin }}$ isobars and the equilibrium degassing trajectory are shown on the $\mathrm{H}_{2} \mathrm{O}-\mathrm{CO}_{2}$ diagram of Fig. 5b. If local gas-melt equilibrium is assumed, the interface melt $\mathrm{H}_{2} \mathrm{O}$ and $\mathrm{CO}_{2}$ concentrations at $\mathrm{P}_{\text {fin }}\left(\mathrm{C}_{\text {new }}\right)$ 
(a)

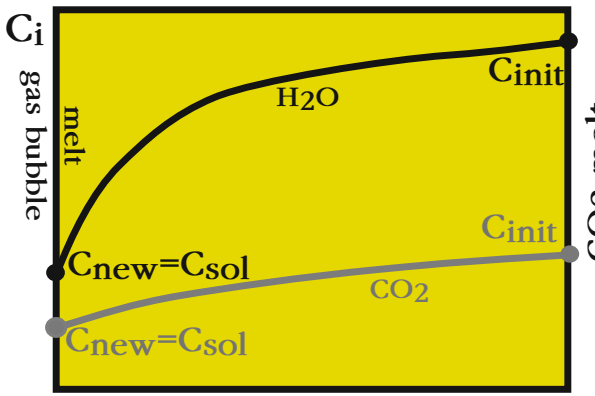

distance from bubble interface (b)

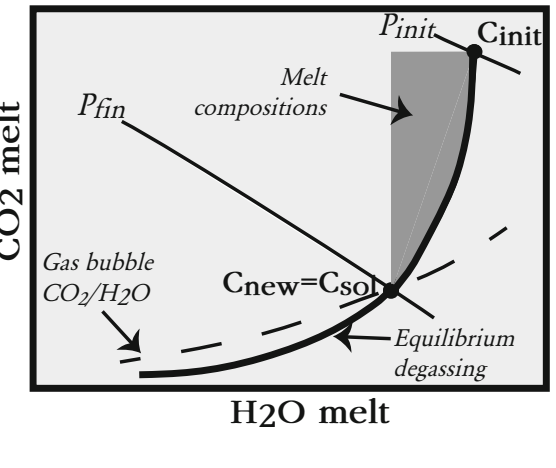

Fig. 5 Schematic illustration of local gas-melt equilibrium. a detail of the gas-melt interface region in a concentration $\left(\mathrm{C}_{\mathrm{i}}\right)$ versus distance diagram where $\mathrm{C}_{\mathrm{i}}$ refers to the volatile concentration in the melt. The gas bubble is on the left. The two curves are melt volatile concentration profiles for $\mathrm{H}_{2} \mathrm{O}$ (black) and $\mathrm{CO}_{2}$ (grey) respectively, generated as a result of diffusion in the melt during decompression from $\mathrm{P}_{\text {init }}$ to $\mathrm{P}_{\text {fin }}$. $\mathrm{C}_{\text {init }}$ give volatile concentrations of the pre-decompression melt, $\mathrm{C}_{\text {new }}$ gas/melt interface volatile concentrations at $\mathrm{P}_{\text {fin }}$ and $\mathrm{C}_{\text {sol }}$ volatile solubilities at $\mathrm{P}_{\text {fin }}$. Black lettering is used for

are equal to their solubilities $\left(\mathrm{C}_{\mathrm{sol}}\right)$ at $\mathrm{P}=\mathrm{P}_{\text {fin }}$ (intersection of the equilibrium degassing curve with the $\mathrm{P}_{\text {fin }}$ isobar, Fig. 5b). Note that diffusive fractionation generates $\mathrm{H}_{2} \mathrm{O}$ and $\mathrm{CO}_{2}$ concentration gradients within the melt (Fig. 5a), the range of possible melt compositions during decompression being represented by the dark grey domain in Fig. 5b. The interface melt is the only melt at equilibrium with the local gas at $\mathrm{P}_{\text {fin }}$ which has a $\mathrm{CO}_{2} / \mathrm{H}_{2} \mathrm{O}$ corresponding to the fluid isopleth on Fig. 5b (e.g., Dixon and Stolper 1995). For a low pressure (e.g., $25 \mathrm{MPa}$ ), the local gas (e.g., a gas bubble nucleated at $\mathrm{P}_{\text {fin }}$ ) is relatively $\mathrm{H}_{2} \mathrm{O}$-rich. In comparison, the pressure integrated gas assuming bulk equilibrium degassing from $\mathrm{P}_{\text {init }}$ to $\mathrm{P}_{\text {fin }}$ would be necessarily less $\mathrm{H}_{2} \mathrm{O}$-rich since most of the $\mathrm{CO}_{2}$ must have been outgassed from the melt. This gas is less $\mathrm{H}_{2} \mathrm{O}$-rich than the pressure integrated gas produced by disequilibrium degassing from $\mathrm{P}_{\text {init }}$ to $\mathrm{P}_{\text {fin }}$ (Fig. 3). Thus, individual bubbles nucleated at $\mathrm{P}_{\text {fin }}$ can have $\mathrm{CO}_{2} / \mathrm{H}_{2} \mathrm{O}$ different from the composition of integrated gases generated continuously during decompression.
$\mathrm{H}_{2} \mathrm{O}$ and grey for $\mathrm{CO}_{2}$. b $\mathrm{H}_{2} \mathrm{O}-\mathrm{CO}_{2}$ diagram illustrating the evolution during decompression and degassing. The black bold curve is the equilibrium degassing trajectory. The two black lines are isobars labelled with initial $\left(\mathrm{P}_{\text {init }}\right)$ and final $\left(\mathrm{P}_{\text {fin }}\right)$ pressures along the decompression path. The dashed curve is the $\mathrm{CO}_{2} / \mathrm{H}_{2} \mathrm{O}$ isopleth passing through $\mathrm{C}_{\mathrm{sol}}$ and it defines the composition of the gas bubble in local equilibrium with the interface melt. The shaded domain gives the range of possible melt compositions generated upon decompression from $\mathrm{P}_{\text {init }}$ down to $\mathrm{P}_{\text {fin }}$

An alternative way to constrain the composition of gas bubbles is illustrated on Fig. 6. It starts from the observation that bubble nucleation is, from a kinetic point of view, an instantaneous process (e.g., Mourtada-Bonnefoi and Laporte 2002, 2004). Nucleation of a gas bubble draws volatiles from the local melt and the possibility that the initial $\mathrm{CO}_{2} / \mathrm{H}_{2} \mathrm{O}$ of the gas bubble is the same as the local melt should be considered. According to this hypothesis, represented schematically on Fig. 6, the local melt next to the nucleated bubble $\left(\mathrm{C}_{\text {new }}\right)$ is volatile-depleted but its $\mathrm{CO}_{2} / \mathrm{H}_{2} \mathrm{O}$ (r, Fig. 6a) is the same than the initial melt $\left(\mathrm{C}_{\text {init }}\right)$. Melt and gas bubble compositions are thus both located on a mixing line between $\mathrm{C}_{\text {init }}$ and $\mathrm{C}_{\text {new }}$ which passes through the origin of the $\mathrm{H}_{2} \mathrm{O}-\mathrm{CO}_{2}$ diagram (Fig. 6b). The net result is the nucleation of individual gas bubbles more $\mathrm{CO}_{2}$-rich than expected from local gas-melt equilibrium (Fig. 5b).

The previous discussion emphasizes the compositional variability of nucleated gas bubbles and the need for their direct analysis in decompression experiments. Comparison between the 
(a)

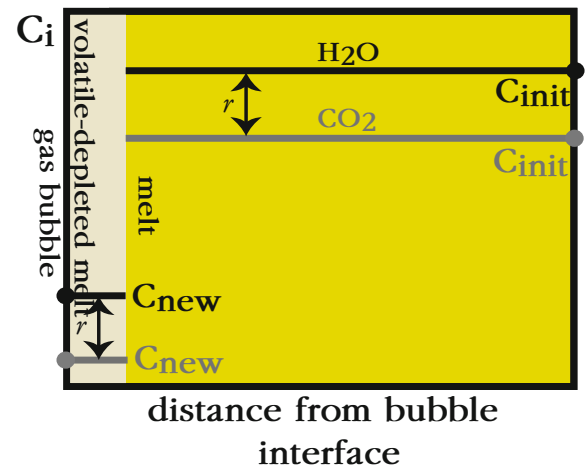

(b)

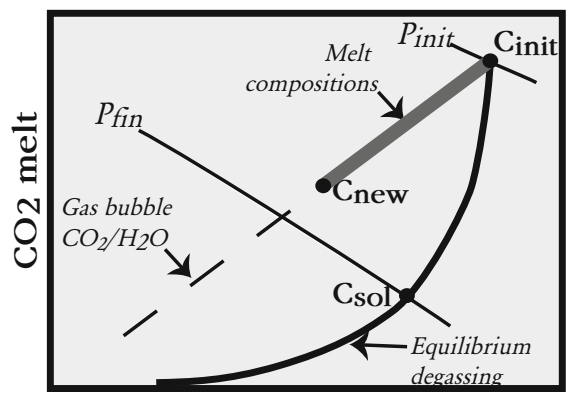

$\mathrm{H}_{2} \mathrm{O}$ melt
Fig. 6 Hypothetical model for the composition of a gas bubble nucleated during decompression of $\mathrm{H}_{2} \mathrm{O}-, \mathrm{CO}_{2}$ bearing basaltic melts. a detail of the gas-melt interface region in a concentration $\left(\mathrm{C}_{\mathrm{i}}\right)$ versus distance diagram where $C_{i}$ refers to the volatile concentration in the melt. The gas bubble is on the left. The two horizontal lines are melt volatile concentrations for $\mathrm{H}_{2} \mathrm{O}$ (black) and $\mathrm{CO}_{2}$ (grey) drawn as straight lines because bubble nucleation is an instantaneous event. The narrow zone near the interface is the melt region depleted in volatiles drawn to form the bubble. $\mathrm{C}_{\text {new }}$ are volatile concentrations in the depleted melt region. Notice that the $\mathrm{H}_{2} \mathrm{O} / \mathrm{CO}_{2}$ ratio (r) is identical in both the depleted and non-depleted melt regions because during nucleation volatiles are drawn from the local melt and the initial $\mathrm{CO}_{2} / \mathrm{H}_{2} \mathrm{O}$ of the gas bubble is the same as the local melt. $\mathrm{C}_{\text {init }}$ give volatile concentrations of the

$\mathrm{CO}_{2} / \mathrm{H}_{2} \mathrm{O}$ of nucleated bubbles and results of gas-melt volatile partitioning models (e.g., Dixon and Stolper 1995; Papale et al. 2006) would provide a crucial test of the local gas-melt equilibrium model (Fig. 5). If the nucleated bubbles prove to be $\mathrm{CO}_{2}$-rich, then alternative models of control of gas composition would be supported (Fig. 6). One important aspect is that, in $\mathrm{CO}_{2-}$ bearing systems, bubble nucleation during decompression is continuous, occurring over a large pressure range (Le Gall and Pichavant 2016a, b). This is because $\mathrm{CO}_{2}$-bearing melts are volatile-supersaturated (Fig. 1) and, so, the driving force for nucleation of new bubbles is always present. Thus, decompression of $\mathrm{CO}_{2}$-bearing melts continuously leads to the nucleation of new bubbles, which increases the relevance of the hypothetical mechanism illustrated in Fig. 6. pre-decompression melt, $\mathrm{C}_{\text {new }}$ gas/melt interface volatile concentrations left after bubble nucleation at $\mathrm{P}_{\text {fin }}$. Black lettering is used for $\mathrm{H}_{2} \mathrm{O}$ and grey for $\mathrm{CO}_{2}$. b $\mathrm{H}_{2} \mathrm{O}-\mathrm{CO}_{2}$ diagram illustrating the evolution during decompression and degassing. The black bold curve gives the schematic location of the theoretical equilibrium degassing trajectory. The two black lines are isobars labelled with initial $\left(\mathrm{P}_{\text {init }}\right)$ and final $\left(\mathrm{P}_{\text {fin }}\right)$ pressures along the decompression path. Melts produced as a result of decompression and bubble nucleation plot on the straight line joining $\mathrm{C}_{\text {init }}$ and $\mathrm{C}_{\text {new }}$. This line passes through the origin of the diagram because both $\mathrm{C}_{\text {init }}$ and $\mathrm{C}_{\text {new }}$ have the same $\mathrm{CO}_{2} / \mathrm{H}_{2} \mathrm{O}$ ratio. Note that the location of $\mathrm{C}_{\text {new }}$ along this line is arbitrary. The $\mathrm{CO}_{2} /$ $\mathrm{H}_{2} \mathrm{O}$ ratio of the gas bubble (dashed line) is also the same as $\mathrm{C}_{\text {init }}$ and $\mathrm{C}_{\text {new }}$. It is higher than the gas bubble controlled by local gas-melt equilibrium (Fig. 5)

\section{Discussion and Perspectives for Gas Monitoring}

\subsection{Degassing Processes}

Experimental simulations show that, for ascent rates expected in natural systems, equilibrium degassing occurs in pure $\mathrm{H}_{2} \mathrm{O}$ melts. In contrast, results for $\mathrm{CO}_{2}$-bearing melts conclusively demonstrate that degassing generates melt volatile concentrations out of equilibrium. The experimental database supporting this conclusion has recently expanded. It now includes basaltic and rhyolitic melts, and S-bearing as well as $\mathrm{S}$-free systems. Several of those experimental decompression studies have been scaled to natural systems so that results are realistic and 
applicable. The decompression experiments on Stromboli basalt cover ascent rates ranging from 0.25 to $3 \mathrm{~m} / \mathrm{s}$ (Pichavant et al. 2013; Le Gall and Pichavant 2016a, b; Le Gall et al. 2015a), well in the range of current estimates for basaltic magmas (e.g., Rutherford 2008; Peslier et al. 2015). An ascent rate approximately 10 times faster was used by Yoshimura (2015). Therefore, in the case of basaltic magmas, equilibrium degassing should be viewed more as a reference situation rather than as a general mechanism. This is quite a change in paradigm which has major implications for how gas signals are interpreted.

One remaining issue concerns the role of crystals on bubble nucleation, heterogeneous rather than homogeneous. All decompression studies considered in this paper were performed on very crystal-poor, if not totally crystal-free, melts and bubble nucleation appears to be mostly homogeneous. Crystals present in experimental basaltic products include $\mathrm{Fe}-\mathrm{Ti}$ oxides (Le Gall and Pichavant 2015b) and rare Fe sulphides (Le Gall et al. 2015a). Le Gall and Pichavant (2015b) have documented heterogeneous nucleation of bubbles on Fe-Ti oxide crystals (and also on Fe sulphides, Le Gall et al. 2015a). Recently, Shea (2017) has stressed the importance of magnetite as a key mineral phase promoting heterogeneous bubble nucleation in natural magmas. However, $\mathrm{Fe}$ oxide phenocrysts and sulphides are uncommonly present in amounts exceeding a few vol.\% in natural magmas. This led Le Gall and Pichavant (2015b) to conclude that heterogeneous bubble nucleation is not an important mechanism in basaltic melts if driven by $\mathrm{Fe}$ oxides. Yet, heterogeneous nucleation on silicate phases is still an open question. For example, olivine, clinopyroxene and plagioclase are typical phenocrysts and microlites in Stromboli basalts (e.g., Pichavant et al. 2011). On the basis of limited textural evidence, Pichavant et al. (2013) ruled out the possibility of heterogeneous nucleation of gas bubbles on clinopyroxene and olivine crystals. However, additional investigations seem warranted to guarantee full applicability of the decompression experiments above.
Disequilibrium degassing, as documented in the experiments, is the consequence of the anomalous behaviour of $\mathrm{CO}_{2} . \mathrm{CO}_{2}$-supersaturated melts are systematically generated during decompression. The interpretation suggested by Pichavant et al. (2013) and quantitatively formulated by Yoshimura (2015) is that, because of its restricted diffusive mobility within the melt, $\mathrm{CO}_{2}$ has limited access to the gas phase for timescales typical of magma ascent. However, our knowledge of volatile diffusivities in silicate melts is still very fragmentary. There are very few diffusivity data for $\mathrm{H}_{2} \mathrm{O}$ and $\mathrm{CO}_{2}$ on the same melt. $\mathrm{S}$ is another volatile which reputedly has a slow diffusivity in silicate melts. Yet, the behaviour of $\mathrm{S}$ during degassing differs from that of $\mathrm{CO}_{2}$, although we are still short of S solubility data for basaltic melts (e.g., Lesne et al. 2015). Acquisition of fundamental data (especially volatile diffusivity and solubility data for basaltic melts) is needed for the elaboration of more detailed interpretations of the decompression experiments. Future magma ascent models should also incorporate the textural complexities associated with the vesiculation process.

\subsection{Gases as Unrest Signals}

Pre-eruptive changes in gas ratios have been observed at several basaltic volcanoes such as Stromboli (Burton et al. 2007; Aiuppa et al. 2010), Etna (Aiuppa et al. 2007) and Villarrica (Aiuppa et al. 2017) among others. Transition from passive degassing to more explosive paroxysmal eruption regimes is marked by temporal increases of the $\mathrm{CO}_{2} / \mathrm{SO}_{2}$ gas ratio in the volcanic plume. In some cases, the $\mathrm{CO}_{2} / \mathrm{SO}_{2}$ variations are correlated with a decrease of the $\mathrm{H}_{2} \mathrm{O} / \mathrm{CO}_{2}$ gas ratio (e.g., Aiuppa et al. 2017). These variations in volcanic gas ratios have been generally interpreted to reflect different pressures of gas-melt segregation in the conduit, high $\mathrm{CO}_{2} /$ $\mathrm{SO}_{2}$ (and low $\mathrm{H}_{2} \mathrm{O} / \mathrm{CO}_{2}$ ) indicating deep conditions and low $\mathrm{CO}_{2} / \mathrm{SO}_{2}$ (and high $\mathrm{H}_{2} \mathrm{O} / \mathrm{CO}_{2}$ ) shallow conditions (e.g., Edmonds 2008; Burton 
et al. 2007; Allard 2010; Aiuppa et al. 2017). In this approach, the pressure-dependent evolution of the gas phase exsolved upon magma ascent and decompression is calculated by using volatile saturation codes (Newman and Lowenstern 2002; Moretti and Papale 2004; Papale et al. 2006; Burgisser et al. 2015). This implicitly assumes chemical equilibrium between gas and melt, an assumption which, as shown above, is now largely questioned. If disequilibrium magma degassing is accepted, then the consequences for the interpretation of gas signals need to be examined.

Firstly, one might argue that gas-melt equilibrium can persist at local scale, despite disequilibrium at larger scales. Thus, volatile saturation codes could still be used and applied to local gas and melt compositions, for example to model the composition of unconnected bubbles nucleated within the melt. In contrast, volcanic gases necessarily require, to be sampled, that the magma is permeable and, so, that the gas phase is connected. It is quite possible that the gases sampled are mixtures of different components, either integrated from several discrete degassing events along ascent or issued from different parts of the plumbing system. Therefore, volcanic gases are probably more representative of integrated compositions as discussed above than to compositions of local gases. We have shown previously that individual bubbles with compositions defined by local gas-melt equilibrium at a given pressure (Fig. 5) can have $\mathrm{CO}_{2} / \mathrm{H}_{2} \mathrm{O}$ different from integrated gases generated continuously during decompression (Fig. 3). We conclude to the limited applicability of local gas melt equilibrium to interpret volcanic gas ratios.

Secondly, disequilibrium gas-melt degassing due to $\mathrm{CO}_{2}$ retention within the melt implies that $\mathrm{CO}_{2} / \mathrm{SO}_{2}$ and $\mathrm{H}_{2} \mathrm{O} / \mathrm{CO}_{2}$ gas ratios can no longer be directly related to pressures of gas-melt segregation. Calculations using the diffusive fractionation model (Fig. 3) show that the pressure integrated gases have a higher $\mathrm{H}_{2} \mathrm{O} / \mathrm{CO}_{2}$ (and also presumably a lower $\mathrm{CO}_{2} / \mathrm{SO}_{2}$ because $\mathrm{CO}_{2}$ is retained within the melt) than the same gases calculated assuming equilibrium with the melt (Fig. 3). This demonstrates the possibility of changing the gas ratios depending on the degassing mechanism (equilibrium vs. disequilibrium). It is worth emphasizing that disequilibrium degassing associated with $\mathrm{CO}_{2}$ retention produces integrated fluids that are less, not more, $\mathrm{CO}_{2}$-rich (Fig. 3).

The $\mathrm{CO}_{2}$-rich gases observed on basaltic volcanoes have been generally attributed to deep-seated processes such as fluxing of $\mathrm{CO}_{2}$ or arrival of $\mathrm{CO}_{2}$-rich magmas (e.g., Aiuppa et al. 2010, 2017; Allard 2010). In contrast, the degassing mechanism of Fig. 6 (although it needs validation from direct analysis of gas bubbles in decompression experiments) allows $\mathrm{CO}_{2}$-rich gas bubbles to be generated at low pressures. It also provides an example of how gas ratios can be changed at constant pressure depending on the degassing mechanism. The initially $\mathrm{CO}_{2}$-rich bubbles (Fig. 6) will probably shift rapidly with time toward lower $\mathrm{CO}_{2} / \mathrm{H}_{2} \mathrm{O}$ because of preferential diffusion of $\mathrm{H}_{2} \mathrm{O}$ from the melt. However, nucleation is a continuous process in $\mathrm{CO}_{2}$-bearing basaltic melts (Le Gall and Pichavant 2016a, b) and reequilibration of previously nucleated bubbles by diffusion will be accompanied by the nucleation of new $\mathrm{CO}_{2}$-rich bubbles.

We conclude that future developments in the interpretation of gas data require progress from both sides, experimental and volcanological. Some crucial experimental information at small scale is still missing such as the composition of individual gas bubbles nucleated in the decompression experiments and the influence of crystals on bubble nucleation. In parallel, at larger scales, the representativity and the significance of the gas phase sampled on active basaltic volcanoes needs to be better demonstrated, for example by combining gas measurements with detailed textural studies of eruption products. It is expected that future work will narrow the gap in scales between experiments and gas measurements to refine interpretations of gas compositions as unrest signals. 
Acknowledgements This paper has benefited from discussions with P. Allard, C. Martel, N. Metrich, A. Bertagnini, R. Moretti, P. Papale and M. Pompilio, reviews by $\mathrm{R}$. Brooker and $\mathrm{F}$. Wadsworth and from editorial comments by B. Scheu. Discussion with S. Yoshimura was helpful. The VUELCO consortium provided a scientifically demanding and interdisciplinary forum for the elaboration of ideas developed in this study. The Ph.D. thesis of NLG was supported by the VUELCO project.

\section{References}

Aiuppa A, Moretti R, Federico C, Giudice G, Gurrieri S, Liuzzo M, Papale P, Shinohara H, Valenza M (2007) Forecasting Etna eruptions by real-time observation of volcanic gas composition. Geology 35:1115-1118

Aiuppa A, Bertagnini A, Metrich N, Moretti R, Di Muro A (2010) A model of degassing for Stromboli volcano. Earth Planet Sci Lett 295:195-204

Aiuppa A, Bitetto M, Francofonte V, Velasquez G, Bucarey Parra C, Giudice G, Liuzzo M, Moretti R, Moussallam Y, Peters N, Tamburello G, Valderrama OA, Curtis A (2017) $\mathrm{A} \mathrm{CO}_{2}$-gas precursor to the March 2015 Villarrica volcano eruption. Geochem Geophys Geosyst 18:2120-2132

Allard P (2010) A $\mathrm{CO}_{2}$-rich gas trigger of explosive paroxysms at Stromboli basaltic volcano, Italy. J Volcanol Geotherm Res 189:363-374

Aubaud C, Pineau F, Jambon A, Javoy M (2004) Kinetic disequilibrium of $\mathrm{C}, \mathrm{He}, \mathrm{Ar}$ and carbon isotopes during degassing of mid-ocean ridge basalts. Earth Planet Sci Lett 222:391-406

Burgisser A, Alletti M, Scaillet B (2015) Simulating the behavior of volatiles belonging to the $\mathrm{C}-\mathrm{O}-\mathrm{H}-\mathrm{S}$ system in silicate melts under magmatic conditions with the software D-Compress. Comput Geosci 79:1-14

Burton M, Allard P, La Spina A, Murè F (2007) Magmatic gas composition reveals the source depth of slug-driven strombolian explosive activity. Science 317:227-230

Christopher T, Edmonds M, Humphreys MCS, Herd RA (2010) Volcanic gas emissions from Soufrière Hills Volcano, Montserrat 1995-2009, with implications for mafic magma supply and degassing. Geophys Res Lett 37: L00E04. https://doi.org/10.1029/2009g1041325

Dixon JE, Stolper EM (1995) An experimental study of water and carbon dioxide solubilities in mid-ocean ridge basaltic liquids. Part II. Applications to degassing. J Petrol 36:1633-1646

Edmonds M (2008) New geochemical insights into volcanic degassing. Philos Trans R Soc A 366:4559-4579

Edmonds M, Aiuppa A, Humphreys M, Moretti R, Giudice G, Martin RS, Herd RA, Christopher T (2010) Excess volatiles supplied by mingling of mafic magma at an andesite arc volcano. Geochem Geophys Geosyst 11:Q04005. https://doi.org/10.1029/2009GC002781

Fiege A, Behrens H, Holtz F, Adams F (2014) Kinetic vs. thermodynamic control of degassing of H2O$\mathrm{S} \pm$ Cl-bearing andesitic melts. Geochim Cosmochim Acta 125:241-264

Gonnermann HM, Manga M (2005) Non-equilibrium magma degassing: results from modelling of the ca. 1340 AD eruption of Mono craters, California. Earth Planet Sci Lett 238:1-16

Head JW III, Wilson L (2003) Deep submarine pyroclastic eruptions: theory and predicted landforms and deposits. J Volc Geotherm Res 121:155-193

Le Gall N, Pichavant M (2015b) Heterogeneous bubble nucleation on $\mathrm{Fe}-\mathrm{Ti}$ oxides in $\mathrm{H}_{2} \mathrm{O}-$ and $\mathrm{H}_{2} \mathrm{O}-\mathrm{CO}_{2}-$ bearing basaltic melts. (In preparation)

Le Gall N, Pichavant M (2016a) Homogeneous bubble nucleation in $\mathrm{H} 2 \mathrm{O}$ - and $\mathrm{H}_{2} \mathrm{O}-\mathrm{CO}_{2}$-bearing basaltic melts: results of high temperature decompression experiments. J Volcanol Geotherm Res 327:604-621

Le Gall N, Pichavant M (2016b) Effect of ascent rate on homogeneous bubble nucleation in the system basalt- $\mathrm{H}_{2} \mathrm{O}-\mathrm{CO}_{2}$ : Implications for Stromboli volcano. Am Mineral 101:1967-1985

Le Gall N, Pichavant M, Di Carlo I, Scaillet B (2015a) Sulfur partitioning between melt and fluid during degassing of ascending C-O-H-S-bearing basaltic magma: an experimental study. In preparation

Lensky NG, Niebo RW, Holloway JR, Lyakhovsky V, Navon O (2006) Bubble nucleation as a trigger for xenolith entrapment in mantle melts. Earth Planet Sci Lett 245:278-288

Lesne P, Scaillet B, Pichavant M, Iacono-Marziano G, Bény J-M (2011) The $\mathrm{H}_{2} \mathrm{O}$ solubility of alkali basaltic melts: an experimental study. Contrib Mineral Petrol 162:133-151

Lesne P, Scaillet B, Pichavant M (2015) The solubility of sulphur in hydrous basaltic melts. Chem Geol 418:104-116

Metrich N, Bertagnini A, Di Muro A (2010) Conditions of magma storage, degassing and ascent at Stromboli: new insights into the volcanic plumbing system with inferences on the eruptive dynamics. J Petrol 51:603-626

Moretti R, Papale P (2004) On the oxidation state and volatile behaviour in multicomponent gas-melt equilibria. Chem Geol 213:265-280

Mourtada-Bonnefoi CC, Laporte D (2002) Homogeneous bubble nucleation in rhyolitic magmas: an experimental study of the effect of $\mathrm{H}_{2} \mathrm{O}$ and $\mathrm{CO}_{2}$. J Geophys Res 107(B4):2066. https://doi.org/10.1029/2001jb000290

Mourtada-Bonnefoi CC, Laporte D (2004) Kinetics of bubble nucleation in a rhyolitic melt: an experimental study of the effect of ascent rate. Earth Planet Sci Lett 218:521-537

Newman S, Lowenstern JB (2002) VolatileCalc: a silicate melt- $\mathrm{H}_{2} \mathrm{O}-\mathrm{CO}_{2}$ solution model written in Visual Basic for Excel. Comput Geosci 28:597-604 
Papale P, Moretti R, Barbato D (2006) The compositional dependence of the saturation surface of $\mathrm{H}_{2} \mathrm{O}+\mathrm{CO}_{2}$ fluids in silicate melts. Chem Geol 229:78-95

Peslier AH, Bizimis M, Matney M (2015) Water disequilibrium in olivines from Hawaiian peridotites: recent metasomatism, $\mathrm{H}$ diffusion and magma ascent rates. Geochim Cosmochim Acta 154:98-117

Pichavant M, Pompilio M, D’Oriano C, Di Carlo I (2011) The deep feeding system of Stromboli, Italy: insights from a primitive golden pumice. Eur $\mathrm{J}$ Miner 23:499-517

Pichavant M, Di Carlo I, Rotolo SG, Scaillet M, Burgisser A, Le Gall N, Martel C (2013) Generation of $\mathrm{CO}_{2-}$ rich melts during basalt magma ascent and degassing. Contrib Mineral Petrol 166:545-561

Rutherford MJ (2008) Magma ascent rates. In: Putirka KD, Tepley F (eds) Minerals, inclusions and volcanic processes. Mineralogical Society of America Reviews in Mineralogy vol 69, pp 241-271

Open Access This chapter is licensed under the terms of the Creative Commons Attribution 4.0 International License (http://creativecommons.org/licenses/by/4.0/), which permits use, sharing, adaptation, distribution and reproduction in any medium or format, as long as you give appropriate credit to the original author(s) and the source, provide a link to the Creative Commons license and indicate if changes were made.
Shea T (2017) Bubble nucleation in magmas: A dominantly heterogeneous process? J Volcanol Geotherm Res 343:155-170

Sparks RSJ, Barclay J, Jaupart C, Mader HM, Phillips JC (1994) Physical aspects of magmatic degassing I. Experimental and theoretical constraints on vesiculation. In: Carroll MR, Holloway JR (eds) Volatiles in Magmas. Mineralogical Society of America Reviews in Mineralogy, vol 30, pp 413-445

Yoshimura S (2015) Diffusive fractionation of $\mathrm{H}_{2} \mathrm{O}$ and $\mathrm{CO}_{2}$ during magma degassing. Chem Geol 411:172-181

Zhang Y, Ni H (2010) Diffusion of H, C, and O components in silicate melts. In: Zhang Y, Cherniak DJ (eds) Diffusion in minerals and melts. Mineralogical Society of America Reviews in Mineralogy vol 72, pp 171-225
The images or other third party material in this chapter are included in the chapter's Creative Commons license, unless indicated otherwise in a credit line to the material. If material is not included in the chapter's Creative Commons license and your intended use is not permitted by statutory regulation or exceeds the permitted use, you will need to obtain permission directly from the copyright holder. 